\title{
The widespread influence of the Rescorla-Wagner model
}

\author{
SHEPARD SIEGEL and LORRAINE G. ALLAN \\ McMaster University, Hamilton, Ontario, Canada
}

\begin{abstract}
The theory of Pavlovian conditioning presented by Robert Rescorla and Allan Wagner in 1972 (the Rescorla-Wagner model) has been enormously important in animal learning research. It also has been applied in a variety of areas other than animal learning. We summarize the contribution of the Rescorla-Wagner model to research in verbal learning, social psychology, human category learning, human judgments of correlational relationships, transitive inference, color aftereffects, and physiological regulation. We conclude that there have been few models in experimental psychology as influential as the Rescorla-Wagner model.
\end{abstract}

The late 1960s was an exciting time for investigators of basic associative processes. Challenges to the view that pairing was sufficient to establish an association between events were coming from many quarters. Robert Rescorla, a new $\mathrm{PhD}$ from the University of Pennsylvania, published his influential paper suggesting that the contingency (or correlation) between events, rather than contiguity (or pairing), was the crucial factor in establishing associations (Rescorla, 1967). Leon Kamin, at McMaster University, reported a new phenomenon, "blocking," and rediscovered an old one, "overshadowing," both of which were further demonstrations that a simple pairing analysis of classical conditioning was apparently inadequate (Kamin, 1968). Allan Wagner and colleagues, at Yale University, reported another phenomenon, "cue validity," that made essentially the same point: There are conditions under which conditional and unconditional stimuli (CSs and UCSs) are paired, but apparently little is learned about the relationship between them (Wagner, Logan, Haberlandt, \& Price, 1968).

Rescorla assumed a position at Yale University, where he collaborated with Wagner in the development of the model that integrated and made sense of these (and other) then-recent findings about Pavlovian conditioning. Rescorla and Wagner presented their model to Kamin and the other participants at a conference on classical conditioning that was held at McMaster University in May 1969. We now know that the attendees at that conference were present at the inauguration of an important era in conditioning research.

This paper was supported by research grants from the Natural Sciences and Engineering Research Council of Canada to S.S. and L.G.A. It is based, in part, on a presentation to the Winter Conference on Animal Learning, Winter Park, Colorado, 1995. The authors would like to thank Steven Flora for bringing the social psychology applications of the Rescorla-Wagner model to our attention. Correspondence should be addressed to S. Siegel, Department of Psychology, McMaster University, Hamilton, ON, Canada L8S 4K1 (e-mail: siegel@ mcmaster.ca).
The conference was organized by Abraham H. Black and William F. Prokasy, who co-edited a volume based on the conference presentations. That volume contained the widely cited presentation of the Rescorla-Wagner model (Rescorla \& Wagner, 1972). Wagner and Rescorla elaborated the model to instances of inhibitory conditioning at a conference on inhibition held at the University of Sussex in April 1971. The proceedings of that conference provide the other seminal discussion of the model (Wagner \& Rescorla, 1972).

\section{THE RESCORLA-WAGNER MODEL}

Not all stimuli present during learning subsequently control behavior. Factors such as the previous history of the stimuli, and their relative saliences, importantly determine whether or not they will be effective. Thus, if a particular CS (say, a light) has been associated with a UCS, and the light subsequently is compounded with a second CS (say, a tone), with this light + tone compound still being paired with the UCS, little is learned about the tone (despite extensive tone-UCS pairings). That is, prior training with one component of a compound will "block" the conditioning of a second component; in this example, the light blocks the tone. Kamin $(1968,1969 a, 1969 b)$ extensively investigated this "blocking" phenomenon.

Kamin also further studied "overshadowing," a phenomenon described by Pavlov (1927, pp. 142-143 and 269-270). In the example of blocking, the light was pretrained prior to being compounded with the tone, and subjects learned little about the tone - the added element. Sometimes, even if there is no prior training of an element of a compound CS, subjects will still learn little about one of the elements. This occurs if one element is more "salient" than the other (other things being equal, a subject trained with a more salient CS will learn more rapidly than a subject trained with a less salient CS). If a light CS is more salient than a tone CS, the effect of pairing a UCS with the light + tone compound will be to strongly associate the light with the UCS, with little as- 
sociative strength developing between the tone and the UCS (the light overshadows the tone).

Prior to Kamin's research, and the development of the Rescorla-Wagner model, most of these findings had been explained by a selective attention mechanism (e.g., Lawrence, 1963); stimuli not attended to are functionally absent. Thus, in the overshadowing example described above, subjects fully attend to the more salient light, and attend little if at all to the less salient tone, and little is learned about the tone-UCS relationship. However, some Pavlovian conditioning findings indicating that not all simultaneously presented CSs paired with a UCS come to elicit conditional responses (CRs) were not readily explicable by an attentional mechanism (Kamin, 1969a, 1969b). Kamin's intuition was that subjects learn about events only to the extent that they are "surprising." In terms of Pavlovian conditioning, the reason why certain CS-UCS associations may not be formed is not because the subject does not attend to the CS; rather, it is because the UCS is already signaled by other CSs, and thus is not surprising. Kamin's notion that UCSs are effective to the extent that they are surprising was captured by the Rescorla-Wagner model.

The model is very successful in dealing with many variables that affect compound conditioning effects such as blocking and overshadowing. It integrates many other conditioning phenomena (e.g., contingency effects, Rescorla, 1967) with compound conditioning effects by treating context cues (i.e., the environment in which conditioning occurs) as it does explicit CSs. Thus, most conditioning preparations, even those that nominally have only a single CS, are treated the same as compound conditioning preparations; the UCS may be presented in some relationship with only the implicit context CS (i.e., the UCS is presented in the conditioning context at times when the explicit CS is not presented), or with a compound CS (i.e., the UCS paired with the explicit CS is also paired with the simultaneously presented context cues). When a compound CS is paired with a UCS, each element of the compound competes for the limited amount of associative strength that can be supported by the UCS. This asymptotic level of associative strength, $\lambda$, is proportional to the intensity of the UCS.

In the years since the model has been proposed, it has inspired considerable research, and thus has received extensive scrutiny. It is apparent that the model has enjoyed many successes, and it also has many shortcomings. It is not our purpose to critically evaluate the model. That has been done, both some years ago (Walkenbach \& Haddad, 1980) and more recently (Miller, Barnet, \& Grahame, 1995). Rather, our purpose is to summarize the influence of the model in many areas of psychology.

The model has become an integral part of animal learning. Its influence is apparent in almost all contemporary animal learning texts. These texts discuss both the successes and shortcomings of the model, but are laudatory with respect to the influence and power of the model. To cite just a few more-or-less arbitrarily selected examples:
The Rescorla-Wagner model has proved to be one of the most remarkable and influential models in psychology. (Lieberman, 1990, p. 116)

The model may prove to be a major landmark in the development of our understanding of learning. (Lieberman, 1990, p. 134)

Their [Rescorla and Wagner's] model is simple and reasonable, and it works. (Malone, 1991, p. 302)

[The Rescorla-Wagner model is] one of the most famous theories of classical conditioning. (Mazur, 1994, p. 88)

As the first formal theory that attempted to predict when a US will promote associative learning, it is guaranteed a prominent place in the history of psychology. (Mazur, 1994, p. 96)

Of course, in the quarter-century since the model was presented there have been other analyses of Pavlovian conditioning. However, it is an affirmation of the importance of the Rescorla-Wagner formulation that "all subsequent attempts to explain Pavlovian conditioning have in one way or the other been responses to apparent shortcomings or limitations of the Rescorla-Wagner theory" (Schwartz \& Robbins, 1995, p. 113). Indeed, some of these responses to the "shortcomings" have led to major theoretical developments. One reason why the model "works" is because it treats the context in which conditioning occurs as it does explicit CSs. Dissatisfaction with this approach, and evidence that context cues may be fundamentally different from phasic cues, has led to the development of a major literature on modulatory mechanisms in Pavlovian conditioning (see review by Swartzentruber, 1995). One reason why the model is simple is because it does not incorporate temporal variables. Evidence that temporal variables are crucial to the course of conditioning has led to the substantial advancements of scalar expectancy theory (see, e.g., Cooper, 1991; Gibbon, 1991).

The authors of the Rescorla-Wagner model realized its limitations (see, e.g., James \& Wagner, 1980; Wagner \& Rescorla, 1972; Zimmer-Hart \& Rescorla, 1974), and proposed alternatives (see, e.g., Wagner, 1981; Wagner $\&$ Brandon, 1989). Many other investigators have modified and elaborated the 1972 version of the RescorlaWagner model to make it better able to deal with new situations and new data - often data that resulted from experiments inspired by the model (e.g., Blough, 1975; Chiang, 1993; Daly \& Daly, 1982; Frey \& Sears, 1978; Mackintosh, 1975; Miller \& Matzel, 1988; Pearce \& Hall, 1980). However, "uniformly, all of these newer models are highly complex and/or have their own lists of failures at least as extensive as that of the RescorlaWagner model" (Miller et al., 1995, p. 381).

The Rescorla-Wagner model has not only been a dominant influence in animal learning research, but it has also had substantial impact in other disciplines: "The Rescorla-Wagner model has been the primary export of traditional learning theory to other areas of psychology" 
(Miller et al., 1995, p. 363). The first such export was to the area of verbal learning.

\section{VERBAL LEARNING}

A good deal of verbal learning research has involved paired-associate learning. Subjects study a list of paired items (e.g., nonsense syllables), and are instructed to generate the second, or "response," item when presented with the first, or "stimulus," item (or when presented with some component of the stimulus item). Results of many experiments indicate that not all features of the stimulus item function equally well as retrieval cues for the response item (see review by Rudy, 1974). For example, Postman and Greenbloom (1967) reported that when trigrams serve as paired-associate stimuli, the letter in the first position in the stimulus trigram was more effective than the other letters in eliciting the response item. Other verbal learning researchers have described pairedassociate phenomena that are very similar to the overshadowing and blocking effects seen in animal learning (e.g., Underwood, Ham, \& Ekstrand, 1962, and Richardson \& Stanton, 1972, respectively). These and similar findings have traditionally been attributed to selectiveattention processes (see, e.g., James \& Greeno, 1967; Richardson, 1971). Shortly after the Rescorla-Wagner model was published, Jerry Rudy (1974) described how such paired-associate learning phenomena were similar to conditioning phenomena, and, like the conditioning phenomena, were better explained by the RescorlaWagner model than by a selective-attention process.

Subsequently, Richardson (1976) examined the paired-associate literature to evaluate the extent to which available findings supported either selectiveattentional analyses or Rudy's (1974) elaboration of the Rescorla-Wagner model. The results were inconclusive. Although the Rescorla-Wagner model was clearly superior to alternatives in explaining some paired-associate phenomena, others seemed to require attentional mechanisms. In subsequent years, researchers interested in human memory and cognition have tended to use procedures other than paired-associate learning. Interest has focused on other problems, such as classification strategies, and other approaches, such as connectionist models.

\section{HUMAN CATEGORY LEARNING}

Perhaps the most widely appreciated application of the Rescorla-Wagner model at present is in the area of connectionist (adaptive network) models of category learning. Adaptive networks consist of processing units or nodes connected by weighted unidirectional links of activation. The nodes are separated into layers: an input layer, an output layer, and hidden layers. When a stimulus is presented to the network, a set of input nodes is activated. These nodes pass their weighted activation to nodes in the next layer. The resulting pattern of activation in the output layer corresponds to the estimated out- come. The network then receives feedback regarding the desired output. The weights are adjusted to bring the output closer to the feedback. By repeated cycling through output-feedback pairings, the system "learns" the weights that will achieve the closest match.

Gluck and Bower (1988) described a simple network model for human category learning that is formally equivalent to the Rescorla-Wagner model. This simple network consists of a layer of input nodes, each representing a feature of the exemplar to be categorized, connected in parallel to a layer of output nodes representing the categories. Learning to categorize the exemplars consists of adjusting the weights of the links between the input and output nodes to increase the probability of making correct categorizations. The weights are altered according to the "Least Means Square" (LMS) rule, or the "delta rule," which is mathematically equivalent to the Rescorla-Wagner learning rule (Sutton \& Bardo, 1981).

The utility of the "Rescorla-Wagner/LMS rule" has been demonstrated in many categorization experiments. For example, Gluck and Bower (1988) studied how people categorize hypothetical "patients" with various "symptoms" as having certain "diseases." There were two diseases, one that occurred frequently (the common disease), the other rarely (the rare disease). The probability of each disease conditionalized on the target symptom, however, was the same. Gluck and Bower found that when the target symptom was present, subjects diagnosed the rare disease more often than the common disease, even though the two conditional probabilities were identical. They showed that this result can be simulated by a connectionist network, using the RescorlaWagner learning rule, in which the symptoms are the input and the diagnosis is the output. They concluded that the Rescorla-Wagner/LMS rule was better than alternatives in describing the data. Shanks $(1990,1991)$, in a series of elegant experiments that included many control conditions, reported similar results. He concluded that the human categorization data "parallel results found in animal conditioning experiments and are readily reproduced by the connectionist network model" (Shanks, 1991, p. 433).

\section{HUMAN JUDGMENTS OF CORRELATIONAL RELATIONSHIPS}

There are various procedures used to study how humans judge the relationship (contingency or correlation) between events (see Allan, 1993). The "active procedure" is analogous to instrumental conditioning. With this procedure, the subject may, or may not, make a response (e.g., press a button), and an event (e.g., presentation of a light) may, or may not, occur after the response. The subject is asked to judge the relationship between the response and the event. The "passive procedure" is analogous to Pavlovian conditioning. Events are presented to the subject (e.g., fictitious information about particular foods eaten by a patient, and the occurrence 
of allergic reactions). In this example of the passive procedure, the subject is asked to judge the relationship between the food and the reaction.

Two broad categories of explanations of the effects of contingency manipulations on judgments have received extensive evaluation: rule-based models and associative models (see Allan, 1993; Shanks, 1993). Rule-based models represent organisms as intuitive statisticians who extract contingency information by applying a rule to integrate probabilities or frequencies of events. Associative models postulate that apparent contingency learning is really the result of associations formed between all contiguously presented events.

There is now considerable evidence that the results from many studies are better captured by an associative model, like the Rescorla-Wagner model, than by a variety of rule-based models (see Allan, 1993; Shanks, 1993). The Rescorla-Wagner model, and its descendants (see, e.g., Shanks \& Dickinson, 1987; Van Hamme \& Wasserman, 1994) can account for much of the human contingency data. In particular, the model has been supported by a variety of demonstrations that conditioning-like manipulations have conditioning-like effects. For example, judgments of correlation are affected by signaling contextual manipulations, show changes over trials, and are subject to blocking, conditioned inhibition, and relative cue validity.

The Rescorla-Wagner model has stimulated much of the exciting research concerned with judgments of relationships. The model has prompted the examination of important issues unlikely to have been explored outside the framework of associative models.

As we noted in the previous section, a connectionist model with two layers (input and output) that incorporates the LMS learning rule is mathematically equivalent to the Rescorla-Wagner model. While most of the literature concerned with human judgments of correlational relationships has relied on the language of the RescorlaWagner model, there are recent papers that have reported successful modeling of such judgments within a connectionist framework (e.g., Shanks, 1994).

\section{REASONING}

When informed that $\mathrm{A}$ is related to $\mathrm{B}$ (e.g., $\mathrm{A}>\mathrm{B}$ ) and $B$ is related to $C$ (e.g., $B>C$ ), transitive inference is demonstrated by the ability to infer, from the two premises, the relationship between $\mathrm{A}$ and $\mathrm{C}$ (in this example, $\mathrm{A}>$ C). The development of such inference has been important in theories of child development (Flavell, 1963), and language is crucial in some analyses of this type of reasoning (Clark, 1969; Sternberg, 1980). For example, Sternberg concluded that to solve transitive inference problems, "subjects first decode the linguistic surface structure of the premises into a linguistic deep structure and then recode the linguistic deep structure into a spatial array" (p. 155). However, transitive inference recently has been demonstrated in several nonhuman animals, including chimpanzees, squirrel monkeys, rats, and pigeons (see summaries by Wynne, 1995, in press). Indeed, such inferential abilities likely are important for species other than humans. For example, humans may find their transitive inference abilities useful for choosing items from a restaurant menu (see Sternberg, 1980), but many animals also find it adaptive to rank their preferences for foods in a transitive manner (see Wynne, 1995). Some animals must estimate their social rank with respect to many conspecifics without engaging each of them in aggressive interactions (Wynne, 1995). The fact that transitive inference is seen in a variety of nonhuman animals has motivated the development of models that can explain the phenomenon without recourse to verbal or "mental scaling" mechanisms.

After demonstrating transitive inference in pigeons (the first demonstration in a nonhuman, nonprimate), Fersen, Wynne, Delius, and Staddon (1991) proposed a conditioning analysis of the phenomenon. Couvillon and Bitterman (1992) suggested that the Fersen et al. model was overly complicated. They applied a simple linearoperator model, the Bush-Mosteller model, to account for transitive inference. Wynne (1995) indicated inadequacies of the Bush-Mosteller model in describing some instances of such inference. Wynne evaluated several associative analyses of the available transitive inference data, and suggested that the findings could be better captured by the descendent of the Bush-Mosteller model, the Rescorla-Wagner model: "A Rescorla-Wagner-based model can account for transitive inference under all conditions in the literature" (Wynne, 1995, p. 207).

\section{SOCIAL PSYCHOLOGY}

According to the Rescorla-Wagner model, context cues function as do explicit CSs. Many seemingly complex learning feats (e.g., the apparent ability of animals to calculate the probabilities of the UCS in the presence and in the absence of the CS) can be explained parsimoniously by assuming that context cues compete with the CS for associative strength.

Context effects are also important in social psychology-especially in the area of interpersonal attraction (see, e.g., Berschied, Brothen, \& Graziano, 1976). The extent to which an individual is found to be "attractive" depends on the attractiveness of other simultaneously present individuals. In one experiment, for example, subjects believed that they were engaged in conversations with unseen strangers. The extent to which subjects found a particular stranger attractive (as measured by the alacrity with which subjects initiated conversation with the stranger) was modulated by the presence of other strangers whom the subject already found attractive (Cramer, Weiss, Steigleder, \& Balling, 1985). Cramer et al. drew analogies between classical conditioning variables and variables demonstrated to be important in the formation of interpersonal attraction. On the basis of the RescorlaWagner model, they developed "attraction equations" to interpret their own data, and to reinterpret many other interpersonal attraction findings in social psychology. 
Lanzetta and Orr $(1980,1981)$ presented another application of the Rescorla-Wagner model to social psychology. They suggested that the Rescorla-Wagner model is relevant to understanding the motivational effect of facial expressions. Subjects received galvanic skin response conditioning in which a tone $\mathrm{CS}$ was paired with a shock UCS. The tone CS was compounded with another cuea photograph of a model depicting one of two affective facial expressions ("happy" or "fearful"). The extent of conditioning to the tone depended on the emotional content of the facial expression (e.g., little was learned about a tone that was presented simultaneously with a fearful expression). The authors suggested that their results were similar to overshadowing effects in classical conditioning, and related their findings to the Rescorla-Wagner model.

\section{PERCEPTION}

Conditioning researchers are often occupied by studying the effects of paired presentation of events. Generally these paired events consist of "relatively neutral" sensory CSs and "biologically significant" UCSs. Sometimes both events are sensory (lights, tones, etc.); indeed, the study of paired presentation of sensory events has a long history in learning research (see, e.g., Brogden, 1939; Rescorla \& Durlach, 1981; see also Hall, 1991), and the results of such studies have elucidated associative process. Perception researchers, too, often study the effects of paired presentation of sensory events - typically to elucidate the organization of the visual system. One perceptual phenomenon that results from such sensory pairings has attracted the interest of both learning and perception researchers - the orientation-contingent color aftereffect. This aftereffect was first reported by Celeste McCollough in 1965, and generally is termed the "McCollough effect." The McCollough effect results from pairing grid orientation with color. For example, during an "induction" period the subject is presented with a grid constructed of black-and-green horizontal bars alternating with a grid of black-and-magenta vertical bars. Following such induction, complementary color aftereffects contingent on bar orientation are noted-black-and-white assessment grids appear colored. In this example, the white space between black horizontal bars appears pinkish, and the white space between black vertical bars appears greenish.

Murch (1976) suggested that the McCollough effect is a type of Pavlovian conditioning: "The lined grid in inspection functions as a conditioned stimulus (CS) while color functions as the unconditioned stimulus (UCS). As a result of the pairing of the CS (lined grid) with the UCS (color) a conditioned response (CR) develops so that the adaptive response of the visual system to the color is evoked by the lined grid" (p. 615). There has been considerable controversy about the value of interpreting the McCollough effect as an instance of classical conditioning (see, e.g., Allan \& Siegel, 1986; Dodwell \& Humphrey, 1993; Skowbo, 1984), but there have been many reports supporting this associative analysis of the phenomenon (e.g., Brand, Holding, \& Jones, 1987; Eissenberg, Allan, Siegel, \& Petrov, 1995; Siegel, Allan, \& Eissenberg, 1992; Westbrook \& Harrison, 1984). Many of the experiments evaluating the conditioning interpretation of the McCollough effect have been inspired by the Rescorla-Wagner model. The results of these experiments suggest that the model can account for many aspects of the McCollough effect (and other contingent aftereffects; see Siegel \& Allan, 1992) that are not readily interpretable by alternative formulations.

Although various researchers have offered alternatives to the conditioning analysis of the McCollough effect (e.g., Bedford, 1995; Dodwell \& Humphrey, 1990), we have suggested elsewhere that these alternatives either are not supported by the empirical data (Allan \& Siegel, in press), or are not distinguishable from a Rescorla-Wagnerbased conditioning interpretation (Allan \& Siegel, 1993).

\section{PHYSIOLOGICAL REGULATION}

We live in a highly variable environment that provides many threats to our existence, both external (e.g., ambient temperatures that are too hot or too cold) and internal (e.g., toxic reactions to drugs, or to wastes produced by our cells). We survive because we have mechanisms to detect and correct these disturbances. The process of detecting and correcting deviations from optimal levels of physiological functioning is termed "homeostasis" (Cannon, 1929). It would be impossible to overstate the importance of homeostatic principles in physiology: "Any paper published today, at least in physiology, which is worth the paper it is printed in, should further clarify a homeostatic mechanism" (Langley, 1973, p. 293).

Several researchers have suggested that deviations from optimal levels of functioning are corrected by responses made in anticipation of perturbations ("predictive homeostasis," or "feedforward homeostasis"), as well as by responses unconditionally elicited by perturbations ("reactive homeostasis," or "feedback homeostasis") (see, e.g., Moore-Ede, 1986; Siegel, 1991). The study of predictive or feedforward homeostasis is the study of Pavlovian conditioning: "Feedforward means anticipation. It means responding, not to disturbances, but to stimuli that have been associated with disturbances in the past" (Toates, 1979, p. 99).

Recently, Dworkin (1993) has described how a modified version of the Rescorla-Wagner model may help us to understand the contribution of anticipatory physiological regulatory responses to homeostasis. A "disturbance," which disrupts homeostasis, often has two components: sensory and physiological. For example, eating candy involves both a sweet taste (sensory component) and an elevation in blood sugar (physiological component). The elevation in blood sugar unconditionally elicits homeostatic corrections (e.g., insulin release) that maintain glucose homeostasis. With sufficient experience in eating candy, the sweet taste conditionally elicits 
such gluco-regulatory, homeostatic responses. One of the models that Dworkin has proposed to describe the relationship between unconditional and conditional contributions to homeostasis, the "lumped-parameter conditioned regulation model" (Dworkin, 1993, pp. 59-68), is based on the Rescorla-Wagner model. The lumpedparameter model differs from the Rescorla-Wagner model, however, in the treatment of $\lambda$. In the Rescorla-Wagner model, this parameter, representing the maximum associative strength that can be supported by a given UCS, is based on the UCS magnitude, and is fixed for all trials with that UCS. In Dworkin's regulation model, $\lambda$ is based on the unconditional response (UCR), rather than the UCS; $\lambda$ represents the UCR magnitude on each trial. Thus, as homeostatic responses increasingly attenuate the disturbance, the magnitude of $\lambda$ decreases. This modification of the Rescorla-Wagner model (together with other features derived from the mathematics of control theory) provides a basis for dynamic stability and longterm regulation of bodily functions.

\section{CONCLUSION}

The Rescorla-Wagner model has influenced several generations of psychologists who study basic learning processes. As has been documented in this article, it has also influenced research in many other areas of psychology. The model provides a simple, mechanistic interpretation of seemingly complex phenomena. Its application to such phenomena has not been without criticism. For example, Dodwell and Humphrey (1993) suggested that Allan and Siegel's (1993) application of the RescorlaWagner model to the McCollough effect "attempts to divert modeling to a different direction from the one we find most insightful, not to say compelling" (p. 347). Markovits and Dumas (1992) took exception to Fersen et al.'s (1991) associative analysis of transitive inference in pigeons: "Great care must be taken before it is possible to unambiguously equate complex cognitive abilities with simple information-processing mechanisms" (p. 312). Wynne (in press) cogently addressed such criticisms: "Where once physical scientists were chastised for finding explanations for physical phenomena that did away with the need for God's continuous oversight, so in our times psychologists are criticized for finding explanations for cognitive phenomena at a more basic, mechanistic level."

The Rescorla-Wagner model was developed to explain animal conditioning findings. As has been indicated, the model has spawned many descendants. These newer alternatives better address some conditioning phenomena (Miller et al., 1995), and may better address some findings in areas discussed in this article. Although researchers in many areas outside animal learning have found classic Rescorla-Wagner to be sufficient for their needs, these researchers might also find it useful to examine successors to the Rescorla-Wagner model (e.g., Van Hamme \& Wasserman, 1994).

It would be correct, although incomplete, to suggest that the Rescorla-Wagner model is important because it has wide applicability. In animal conditioning the model has provided a focus for research for over 20 years. When researchers interpret the results of a completed conditioning experiment or think about the manipulations to be used in a future experiment, it has become second nature to think in terms of the Rescorla-Wagner model. It has acquired a stature in the study of learning similar to that acquired by signal detection theory in psychophysics. Although there are criticisms of, and alternatives to, signal detection theory (e.g., Link \& Heath, 1975), it remains preeminent, and provides a useful way to think about many psychophysical issues. Moreover, signal detection theory has been found to be applicable to many areas in addition to the limited domain in which it was first developed; that is, it has become a way to think about issues in areas other than psychophysics (see Swets, 1973, 1988). Similarly, the Rescorla-Wagner model has provided a basis for thinking about issues in areas other than Pavlovian conditioning. There are only a precious few such inspirational contributions in experimental psychology.

\section{REFERENCES}

ALLAN, L. G. (1993). Human contingency judgments: Rule based or associative? Psychological Bulletin, 114, 435-448.

Allan, L. G., \& SiEgel, S. (1986). McCollough effects as conditioned responses: Reply to Skowbo. Psychological Bulletin, 100, 388-393.

Allan, L. G., \& SiEgel, S. (1993). McCollough effects as conditioned responses: Reply to Dodwell and Humphrey. Psychological Review, 100, 342-346.

Allan, L. G., \& Siegel, S. (in press). Contingent color aftereffects: Reassessing old conclusions. Perception \& Psychophysics.

BEDFORD, F. L. (1995). Constraints on perceptual learning: Objects and dimensions. Cognition, 54, 253-297.

Berschied, E., Brothen, T., \& Graziano, W. (1976). Gain-loss theory and the "law of infidelity": Mr. Doting versus the admiring stranger. Journal of Personality \& Social Psychology, 33, 709-718.

BLough, D. S. (1975). Steady state data and a quantitative model of operant generalization and discrimination. Journal of Experimental Psychology: Animal Behavior Processes, 1, 3-21.

Brand, J. L., Holding, D. H., \& Jones, P. D. (1987). Conditioning and blocking of the McCollough effect. Perception \& Psychophysics, 41, 313-317.

Brogden, W. J. (1939). Sensory preconditioning. Journal of Experimental Psychology, 25, 323-332.

CANnon, W. B. (1929). Organization for physiological homeostasis Physiological Reviews, 9, 399-431

Chiang, C.-Y. (1993). A generalization of the Rescorla-Wagner model of conditioning and learning. British Journal of Mathematical \& Statistical Psychology, 46, 207-212.

Clark, H. H. (1969). Linguistic processes in deductive reasoning. Psychological Review, 76, 387-404.

COOPER, L. D. (1991). Temporal factors in classical conditioning. Learning \& Motivation, 22, 129-152.

Couvillon, P. A., \& BitTerman, M. E. (1992). A conventional conditioning analysis of "transitive inference" in pigeons. Journal of Experimental Psychology: Animal Behavior Processes, 18, 308-310.

Cramer, R. E., Weiss, R. F., Steigleder, M. K., \& Balling, S. S. (1985). Attraction in context: Acquisition and blocking of persondirected action. Journal of Personality \& Social Psychology, 49, $1221-1230$.

DALY, H. B., \& DALY, J. T. (1982). A mathematical model of reward and aversive non-reward: Its application in over 30 appetitive learning situations. Journal of Experimental Psychology: General, 111, 441-480.

Dodwell, P. C., \& Humphrey, G. K. (1990). A functional theory of the McCollough effect. Psychological Review, 97, 78-79. 
Dodwell, P. C., \& Humphrey, G. K. (1993). What is important about McCollough effects? A reply to Allan and Siegel. Psychological Review, 100, 347-350.

DWORKIN, B. R. (1993). Learning and physiological regulation. Chicago: University of Chicago Press.

Eissenberg, T., Allan, L. G., Siegel, S., \& Petrov, N. (1995). An associative interpretation of the indirect McCollough effect. Quarterly Journal of Experimental Psychology, 48B, 262-286.

Fersen, L. von, Wynne, C. D. L., Delius, J. D., \& Staddon, J. E. R (1991). Transitive inference formation in pigeons. Journal of Experimental Psychology: Animal Behavior Processes, 17, 334-341.

Flavell, J. (1963). The developmental psychology of Jean Piaget. Princeton, NJ: Van Nostrand.

FREY, P. W., \& SEARS, R. J. (1978). Model of conditioning incorporating the Rescorla-Wagner associative axiom, a dynamic attention process, and a catastrophe rule. Psychological Bulletin, 85, 321-340.

GibBON, J. (1991). Origins of scalar timing. Learning \& Motivation, 22, 3-38.

GLuCK, M. A., \& Bower, G. H. (1988). From conditioning to category learning. Journal of Experimental Psychology: General, 117, 227 247.

HALL, G. (1991). Perceptual and associative learning. Oxford: Oxford University Press, Clarendon Press.

JAMES, C. T., \& GREeno, J. G. (1967). Stimulus selection at different stages of paired associate learning. Journal of Experimental Psychology, 74, 75-83.

JAMES, J. H., \& WAGNER, A. R. (1980). One-trial overshadowing: Evidence of distributed processing. Journal of Experimental Psychology: Animal Behavior Processes, 6, 188-205.

KAmIN, L. J. (1968). "Attention-like" processes in classical conditioning. In M. R. Jones (Ed.), Miami Symposium on the Production of Behavior: Aversive stimulation (pp. 9-33). Miami, FL: University of Miami Press.

Kamin, L. J. (1969a). Predictability, surprise, attention, and conditioning. In B. A. Campbell \& R. M. Church (Eds.), Punishment and aversive behavior (pp. 279-296). New York: Appleton-CenturyCrofts.

KAMIN, L. J. (1969b). Selective association and conditioning. In N. J. Mackintosh \& W. K. Honig (Eds.), Fundamental issues in associative learning. Halifax, NS: Dalhousie University Press.

LANGLEY, L. L. (1973). Homeostasis: Origins of a concept. Stroudsburg, PA: Dowden, Hutchison \& Ross.

LANZETTA, J. T., \& ORR, S. P. (1980). Influence of facial expressions on the classical conditioning of fear. Journal of Personality \& Social Psychology, 39, 1081-1087.

LanzetTa, J. T., \& ORR, S. P. (1981). Stimulus properties of facial expressions and their influence on the classical conditioning of fear Motivation \& Emotion, 5, 225-234.

LAWRENCE, D. H. (1963). The nature of a stimulus: Some relationships between learning and perception. In S. Koch (Ed.), Psychology: A study of a science (Vol. 5, pp. 179-212). New York: McGraw-Hill

Lieberman, D. A. (1990). Learning: Behavior and cognition. Belmont, CA: Wadsworth.

Link, S. W., \& Heath, R. A. (1975). A sequential theory of psychological discrimination. Psychometrika, 40, 77-105.

MACKINTOSH, N. J. (1975). A theory of attention: Variations in the associability of stimuli with reinforcement. Psychological Review, 82, 276-298.

MALONE, J. C. (1991). Theories of learning: A historical approach. Belmont, CA: Wadsworth

Markovits, H., \& Dumas, C. (1992). Can pigeons really make transitive inferences? Journal of Experimental Psychology: Animal Behavior Processes, 18, 311-312.

MAZUR, J. E. (1994). Learning and behavior (3rd ed.). Englewood Cliffs, NJ: Prentice-Hall.

McCollough, C. (1965). Color adaptation of edge-detectors in the human visual system. Science, 149, 1115-1116.

Miller, R. R., Barnet, R. C., \& Grahame, N. J. (1995). Assessment of the Rescorla-Wagner model. Psychological Bulletin, 117, 363 386.

Miller, R. R., \& MATzel, L. D. (1988). The comparator hypothesis: A response rule for the expression of associations. In G. H. Bower
(Ed.), The psychology of learning and motivation (Vol. 22, pp. 5192). San Diego, CA: Academic Press.

MoORE-EdE, M.C. (1986). Physiology of the circadian timing system: Predictive vs. reactive homeostasis. American Journal of Physiology, 350, R735-R752.

Murch, G. M. (1976). Classical conditioning of the McCollough effect: Temporal parameters. Vision Research, 16, 615-619.

Pavlov, I. P. (1927). Conditioned reflexes (G. V. Anrep, Ed. \& Trans.) London: Oxford University Press.

Pearce, J. M., \& HaLL, G. (1980). A model for Pavlovian conditioning: Variations in the effectiveness of conditioned but not unconditioned stimuli. Psychological Review, 87, 332-352.

Postman, L., \& Greenbloom, R. (1967). Conditions of cue selection in the acquisition of paired associate lists. Journal of Experimental Psychology, 73, 91-100.

ResCorLA, R. A. (1967). Pavlovian conditioning and its proper control procedures. Psychological Review, 74, 71-80.

Rescorla, R. A., \& Durlach, P. J. (1981). Within-event learning in Pavlovian conditioning. In N. E. Spear \& R. R. Miller (Eds.), Information processing in animals: Memory mechanisms (pp. 81111). Hillsdale, NJ: Erlbaum.

Rescorla, R. A., \& Wagner, A. R. (1972). A theory of Pavlovian conditioning: Variations in the effectiveness of reinforcement and nonreinforcement. In A. H. Black \& W. F. Prokpsy (Eds.), Classical conditioning II: Current research and theory (pp. 64-99). New York: Appleton-Century-Crofts.

RICHARDSON, J. (1971). Cue effectiveness and abstraction in paired associate learning. Psychological Bulletin, 75, 73-91.

Richardson, J. (1976). Component selection in paired associate learning: Research and theory. American Journal of Psychology, 89, 3-49

Richardion, J., \& Stanton, S. K. (1972). Some effects of learning to a set of components on stimulus selection. American Journal of Psychology, 85, 519-533.

RUDY, J. W. (1974). Stimulus selection in animal conditioning and paired-associate learning: Variations in the associative process. Journal of Verbal Learning \& Verbal Behavior, 13, 282-296.

SChWARtz, B., \& RoBBins, S. J. (1995). Psychology of learning and behavior (4th ed.). New York: Norton.

SHANKS, D. R. (1990). Connectionism and the learning of probabilistic concepts. Quarterly Journal of Experimental Psychology, 42A, 209-237.

Shanks, D. R. (1991). Categorization by a connectionist network. Journal of Experimental Psychology: Learning, Memory, \& Cognition, 17, 433-443.

SHANKS, D. R. (1993). Human instrumental learning: A critical review of data and theory. British Journal of Psychology, 84, 319-354.

SHANKS, D. R. (1994). Human associative learning. In N. J. Mackintosh (Ed.), Animal learning and cognition. San Diego, CA: Academic Press.

Shanks, D. R., \& Dickinson, A. (1987). Associative accounts of causality judgment. In G. H. Bower (Ed.), The psychology of learning and motivation (Vol. 21, pp. 229-261). San Diego, CA: Academic Press.

SIEGEL, S. (1991). Feedforward processes in drug tolerance. In R. G. Lister \& H. J. Weingartner (Eds.), Perspectives in cognitive neuroscience (pp. 405-416). New York: Oxford University Press.

Siegel, S., \& Allan, L. G. (1992). Pairings in learning and perception: Pavlovian conditioning and contingent aftereffects. In.D. Medin (Ed.), The psychology of learning and motivation (Vol. 28, pp. 127160). San Diego, CA: Academic Press.

Siegel, S., Allan, L. G., \& Eissenberg, T. (1992). The associative basis of contingent color aftereffects. Journal of Experimental Psychology: General, 121, 79-94.

Skowвo, D. (1984). Are McCollough effects conditioned responses? Psychological Bulletin, 96, 215-226.

STERNBERG, R. J. (1980). Representation and process in linear syllogistic reasoning. Journal of Experimental Psychology: General, 109, 119-159.

SutToN, R. S., \& Bardo, A. G. (1981). Toward a modern theory of adaptive networks: Expectation and prediction. Psychological Review, 88, 135-170. 
Swartzentruber, D. (1995). Modulatory mechanisms in Pavlovian conditioning. Animal Learning \& Behavior, 23, 123-143.

SwETS, J. A. (1973). The relative operating characteristic in psychology. Science, 182, 990-1000.

SWETS, J. A. (1988). Measuring the accuracy of diagnostic systems. Science, 240, 1285-1293.

TOATES, F. M. (1979). Homeostasis and drinking. Behavioral \& Brain Sciences, 2, 95-139.

Underwood, B. J., Ham, M., \& Ekstrand, B. (1962). Cue selection in paired associate learning. Journal of Experimental Psychology, 64, 405-409.

Van Hamme, L. J., \& Wasserman, E. A. (1994). Cue competition in causality judgments: The role of nonpresentation of compound stimulus elements. Learning \& Motivation, 25, 127-151.

WAGNER, A. R. (1981). SOP: A model of automatic memory processing in animal behavior. In N. E. Spear \& R. R. Miller (Eds.), Information processing in animals: Memory mechanisms (pp. 5-47). Hillsdale, NJ: Erlbaum.

WAGNER, A. R., \& Brandon, S. E. (1989). Evolution of a structured connectionist model of Pavlovian conditioning (AESOP). In S. B Klein \& R. R. Mowrer (Eds.), Contemporary learning theories. Pavlovian conditioning and the status of traditional learning theory (pp. 149-189). Hillsdale, NJ: Erlbaum.

Wagner, A. R., Logan, F. A., Haberlandt, K., \& Price, T. (1968)
Stimulus selection in animal discrimination learning. Journal of Experimental Psychology, 76, 171-180.

WAGNeR, A. R., \& Rescorla, R. A. (1972). Inhibition in Pavlovian conditioning: Application to a theory. In R. A. Boakes \& M. S. Halliday (Eds.), Inhibition and learning (pp. 301-336). London: Academic Press.

WalkenbaCh, J., \& HADDAD, N. F. (1980). The Rescorla-Wagner theory of conditioning: A review of the literature. Psychological Record, 30, 497-509.

WESTBROOK, R. F., \& HaRRISON, W. (1984). Associative blocking of the McCollough effect. Quarterly Journal of Experimental Psychology, 36A, 309-318.

WYNNE, C. D. L. (1995). Reinforcement accounts for transitive inference performance. Animal Learning \& Behavior, 23, 207-217.

WYNNE, C. D. L. (in press). A minimal model of transitive inference. In C. D. L. Wynne \& J. E. R. Staddon (Eds.), Models for action. Hillsdale, NJ: Erlbaum.

Zimmer-Hart, C. L., \& Rescorla, R. A. (1974). Extinction of a Pavlovian conditioned inhibitor. Journal of Comparative \& Physiological Psychology, 86, 837-845.

(Manuscript received August 29, 1995; revision accepted for publication January 25,1996 .) 